\title{
Development and Validation of Reverse-phase High- performance Liquid Chromatography Method for Novel Synthetic Pyridine Derivative
}

\author{
R. S. Dave*, Vipul J. Vyas, Bipinchandra Mahyavanshi \\ Department of Chemistry, Arts, Science \& Commerce College, Pilvai, Gujarat, India
}

\begin{abstract}
Article Info

Volume 8, Issue 3

Page Number : 528-542

\section{Publication Issue}

May-June-2021

\section{Article History}

Accepted : 01 June 2021

Published : 06 June 2021

The study was focused toward synthesis, characterization and quantification of Pyridine derivative by Reverse Phase High Performance Liquid Chromatography method. The synthesis of novel pyridine derivative was carried out by condensation reaction in presence of inert catalyst $\mathrm{K}_{2} \mathrm{CO}_{3}$ and THF solvent. Characterization was done by I.R, 1H-NMR, and HPLC. Based on the spectral data, the structure of novel pyridine derivative was characterized as 5 - (4 - Substituted amino) - 3- Nitrobenzene - 1 - Sulfonyl) - 4, 5, 6, 7 Tetrahydrothieno[3, 2 - C] Pyridine The method validation including precision, accuracy, LOD, robustness, Linearity, and range was developed as per ICH guideline through an efficient isocratic RP-HPLC.It was determined that the above procedure is specified, accurate, precise, robust, and sturdy.

Keywords : RP-HPLC, Pyridine Derivative, Method Development, Validation
\end{abstract}

\section{INTRODUCTION}

The contaminant is defined in the biomedical industry as any additional organic molecule, other than the medicinal compounds or factors, which originates from synthesis or undesirable compounds which persist with Active Pharmaceutical Ingredients (APIs).The contaminant might arise mostly during the formulation phase or after the APIs and compositions have aged. Medication analysis is critical in drug discovery, manufacturing, and clinical usage. Contaminants in small quantities are unavoidable in drug material or dosage form. As a result, their level must be maintained and controlled. They either enhance or reduce the therapeutic properties of the Active Pharmaceutical Ingredient.[1]The HPLC technique is widely used to predict pharmaceutical's unadulterated and dose forms because it is easy, accurate, and repeatable. The International Conference on Harmonization (ICH) defines an impurity characteristic of a drug material as "a representation of the recognized and undiscovered impurities presents in a novel medicinal substance" Contaminants are described in pharmaceutical drugs as "substances inside the product which are not the API itself as well as the 
active ingredient utilized to make it. "Contaminants are identified using a number of chromatographic and spectroscopic approaches, potentially alone or in conjunction with other techniques. [2-4]

Many of the most common heterocyclic compound obtained from natural goods, medicines, including conducting polymers hasthe Pyridine backbone.[5]Most effective methods of synthesizing such heterocycles depend upon amine-carbonyl compound condensation or cycloaddition processes.[6]The present study is centralized on synthetic approach of pyridine derivative and its identification as well as validation using RP-HPLC technique. There are multiple methodologies for identifying and analyzing contaminants, such as TLC, HPTLC, and HPLC.Among others, HPLC has indeed been extensively used throughout the field of contamination monitoring because of the large choice of detectors and stationary phases, as well as its sensitivity and cost-effective separation, have contributed to its many uses.

\section{MATERIALS AND METHODS}

\section{Materials reagents and chemicals:}

\section{4,5,6,7-Tetra hydrothieno [3,2-c] pyridine} hydrochloride, THF, 4-chloro-3-nitro benzene sulfonyl chloride, $\mathrm{K}_{2} \mathrm{CO}_{3}$ Acetonitrile (HPLC Grade),Trifluoroacetic acid, and, DMSO were from Merck Chemicals Pvt. Ltd.Melting points were determined by open capillary method. The NMR spectra were recorded on Bruker model NMR.IR spectra were recordedon Shimadzu FTIR-8400S spectrophotometer using $\mathrm{KBr}$ discmethod. Method validation was performed on Agilent HPLC model.

\section{Synthetic approach:}

In a round bottom flaskTransfer $1.0 \mathrm{~mL}$ (5-4-chloro3-nitrobenzene-1-sulfonyl) $-4,5,6,7-$ tetrahydrothieno $[3,2-\mathrm{C}]$ pyridine was mixed with $\mathrm{DMF}, \mathrm{K} 2 \mathrm{CO} 3$, and 2.0mole morpholin and allowed to sit at room temperature for 45 minutes. The reaction mixture was agitated at $75 \mathrm{C}$ for 3-4 hours at reflux temperature before the solvent was evaporated under reduced pressure. Because the $\mathrm{pH}$ of the combination was higher than 7.0, diluted $\mathrm{HCl}$ was added to lower the $\mathrm{pH}$ to 6.5 and the reaction mixture was stirred for another 2 hours at room temperature. Then, to the resulting residue, add Water and stir for 1 hour at room temperature. The solid was filtered away, then the mixture was triturated with ethanol and strained to obtain the product.The solid was dried under reduced pressure. Yield: 68 \%, M.P $185^{\circ}$ C.in Figure 01.
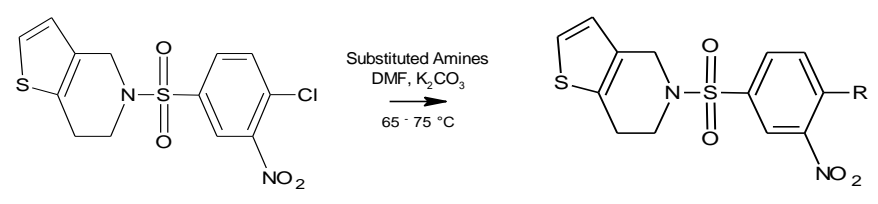

Figure 01 : Synthesis scheme of 5 -[ 4- (morpholin-4yl)- 3- nitrobenzene - 1 - Sulfonyl ] - 4, 5, 6, 7 Tetrahydrothieno [3, 2 - C] Pyridine.

\section{Characterization of synthesized compound:}

Advanced Quantitative Methodologies such as I.R spectra, 1H-NMR, 13C-NMR, and Mass spectrometry were used to describe the synthesized compound. The functional group characterization was carried out on SHIMADZU FTIR 8400 Spectrophotometer withFrequency range of $4000-400 \mathrm{~cm}^{-1}$ through $\mathrm{KBr}$ disc method. NMR data were recorded for $1 \mathrm{H}$ NMR with deuterated solvent and 13C NMR.

\section{HPLC Method development:}

To create a rapid HPLC method for quantifying drug substances with the maximum selectivity, precision, and accuracy different ratio of mobile phases were used. Agilent's chromatographic equipment was utilized to design and validate this method, and it included a Sartorius digital balance and a Mettler Toledo branded balancer, as well as an oven for weighing and heating, and a Spinco ultrasonic bath for degassing and sonication. 


\section{Preparation of standard solution:}

In $25 \mathrm{ml}$ volumetric flask $50 \mathrm{mg}$ standard is transferred after accurately weighed and made up the volume up to the mark with diluent (water:Acetonitrile - 30:70) and mixed well. $1.3 \mathrm{ml}$ solution from the stock solution were taken and made up to $50 \mathrm{ml}$ with mobile phase.

\section{Preparation of Sample Solution:}

The sample solution was prepared by dissolving accurately weighted $50 \mathrm{mg}$ standard active pharma ingredient (API) of synthesis drug in $25 \mathrm{ml}$ volumetric flask up to the mark using diluent (water:Acetonitrile - 30:70).

\section{Chromatographic conditions:}

The separation was done through J'Sphere ODS-H80 (150 mm x $4.6 \mathrm{~mm}$ id, $5 \mu$ particle size) column with gradient mode using two different mobile phases. The gradient system was set using $0.1 \%$ Trifluoroacetic acid as mobile phase -A and Acetonitrile as mobile phase- $B$ in different proportion. The column flow rate and temperature were set correspondingly at 1.0 $\mathrm{mL} / \mathrm{minute}$ and $25{ }^{\circ} \mathrm{C}$. The chromatogram was obtained by measuring the UV absorbance of the eluted analytes with a diode array detector at $220 \mathrm{~nm}$. The injection volume of the auto-sampler was set $20 \mu \mathrm{L}$ and the run time was 60 minutes. The gradient program of system was shown in table 01 .

Table 01: The gradient program of RP-HPLC system

\begin{tabular}{|c|c|c|}
\hline Time & Mobile Phase-A & Mobile Phase-B \\
\hline 0 & 55 & 45 \\
\hline 5 & 55 & 45 \\
\hline 15 & 45 & 55 \\
\hline 25 & 40 & 60 \\
\hline 30 & 35 & 65 \\
\hline 35 & 15 & 85 \\
\hline 40 & 55 & 45 \\
\hline 45 & 55 & 45 \\
\hline
\end{tabular}

\section{(iii) Accuracy:}

The accuracy was tested using a standard solution of synthesized chemical in formulations. The recovery of the recommended approach was examined using the pseudo stimulation technique with three unique measurement range of $50 \%, 100 \%$, and $150 \%$ for this previously identified sample solution having a specific quantity of synthesized chemical.Triplicate assessments of these three levels were reported to estimate the percent recovery and percent relative error.

\section{(iv) Limit of Detection and Limit of Quantification:}

Limit of Detection (LOD) is the smallest amount of drug content that the proposed technology can detect, whereas Limit of Quantification(LOQ) is the smallest quantity that the method can quantify.The guidelines 
recommend a minimal signal-to-noise ratio $(\mathrm{S} / \mathrm{N})$ of greater than 3.3 for LOD and greater than 10 for LOQ.The given formula can hypothetically determine it on the basis of linearity data.

$$
\begin{aligned}
& \mathrm{LOD}=3.3 \sigma / \mathrm{S} \\
& \mathrm{LOQ}=10 \sigma / \mathrm{S}
\end{aligned}
$$

Where $\sigma=$ Residual Standard Deviation of regression line, $\mathrm{S}=$ Slope of regression line.

\section{(v) Linearity and Range:}

The linearity of the analytical method was demonstrated from LOQ to 150 percent of the specification level concentration for the specified degradation and from LOQ to 150 percent of the standard concentration for the respective analyte.Spiking specified degradation products in the range of LOQ to 150 percent of specification limit and analyte in the range of LOQ to 150 percent of standard concentration in diluents yielded a linearity solution level. Six concentrations range from 0.832 to $29.64 \mu \mathrm{g} / \mathrm{ml}(0.832,10.40,15.08,19.76,25.48$ and $29.64 \mathrm{~mL} / 50 \mathrm{~mL}$ ) were used to detect linearity.

\section{III.RESULTS AND DISCUSSION}

The synthesized drug was identified through spectrometric methods and validated by RP-HPLC system. The physicochemical properties of drug were properly shown in Table 02 ,

\section{Physicochemical properties}

Table 02 : Physicochemical Properties
The synthesized drug was identified as 5 -[ 4(morpholin-4-yl)- 3- nitrobenzene - 1 - Sulfonyl ] 4, 5, 6, 7 -Tetrahydrothieno [3, 2 - C] Pyridine. from different spectroscopic data. The physicochemical properties are shown in table 02.The molecular formula of compound was settled as $\mathrm{C}_{17} \mathrm{H}_{19} \mathrm{~N}_{3} \mathrm{~S}_{2} \mathrm{O}_{5}$ which was further verified by mass spectrometric analysis.The ESI-MS data (Figure 06) of compound showed a molecular ion peak at m/z409 $[\mathrm{M}+\mathrm{H}]^{+}$. The IR $(\mathrm{KBr})$ spectrum of synthesized compound showed the absorption bands (Table 03) at $V_{\max } 1458,2916,2854,1350,3092,1535,1458,833 \quad \mathrm{~cm}^{-1}$ indicating the presence of thiophene group, aliphatic $\mathrm{C}-\mathrm{H}$ bond, and aromatic ring in its molecule.A calculation of double bond equivalence revealed the presence of eight degree of unsaturation which was established by the presence of one aliphatic and two aromatic ring and a nitro group in the molecule. The 1H NMR spectrum (Table 04, Figure03) showed the signals for the presence of one aromatic proton at $\delta \mathrm{H}$ 8.293-8.288 $(1 \mathrm{H}, \mathrm{s})$, the singlet nature of the signals has suggested them to be aromatic in nature and the aromatic ring mustbe trisubstituted. In order to confirm the nature of carbon atoms present in compound its 13C NMR spectrum (Table 05, Figure 04) was measured. The multiplicity of carbons determined and found the presence of eight

\begin{tabular}{|c|c|c|c|c|c|c|c|}
\hline \multirow{2}{*}{ Comp. } & \multirow{2}{*}{$\begin{array}{c}\text { Substitution } \\
\mathbf{R}\end{array}$} & \multirow{2}{*}{$\begin{array}{c}\text { Molecular } \\
\text { Formula/Weight }\end{array}$} & \multirow{2}{*}{$\begin{array}{l}\text { M.P. } \\
{ }^{\circ} \mathrm{C}\end{array}$} & \multirow{2}{*}{ Yeild \% } & \multicolumn{3}{|c|}{$\begin{array}{l}\text { \% Composition } \\
\text { Calculated/Found }\end{array}$} \\
\hline & & & & & $\mathrm{C}$ & $\mathrm{H}$ & $\mathbf{N}$ \\
\hline $1 \mathrm{~B}$ & Morpholine & $\begin{array}{c}\mathrm{C}_{17} \mathrm{H}_{19} \mathrm{~N}_{3} \mathrm{~S}_{2} \mathrm{O}_{5} \\
409\end{array}$ & 185 & 68 & $\begin{array}{l}49.86 \\
49.85\end{array}$ & $\begin{array}{l}4.68 \\
4.65\end{array}$ & $\begin{array}{l}10.26 \\
10.23\end{array}$ \\
\hline
\end{tabular}
methylene, one methine carbons. 


\section{I.R Spectra}

IR spectra were recorded on Shimadzu FTIR-8400S spectrophotometer using $\mathrm{KBr}$ disc method shown in figure 02.

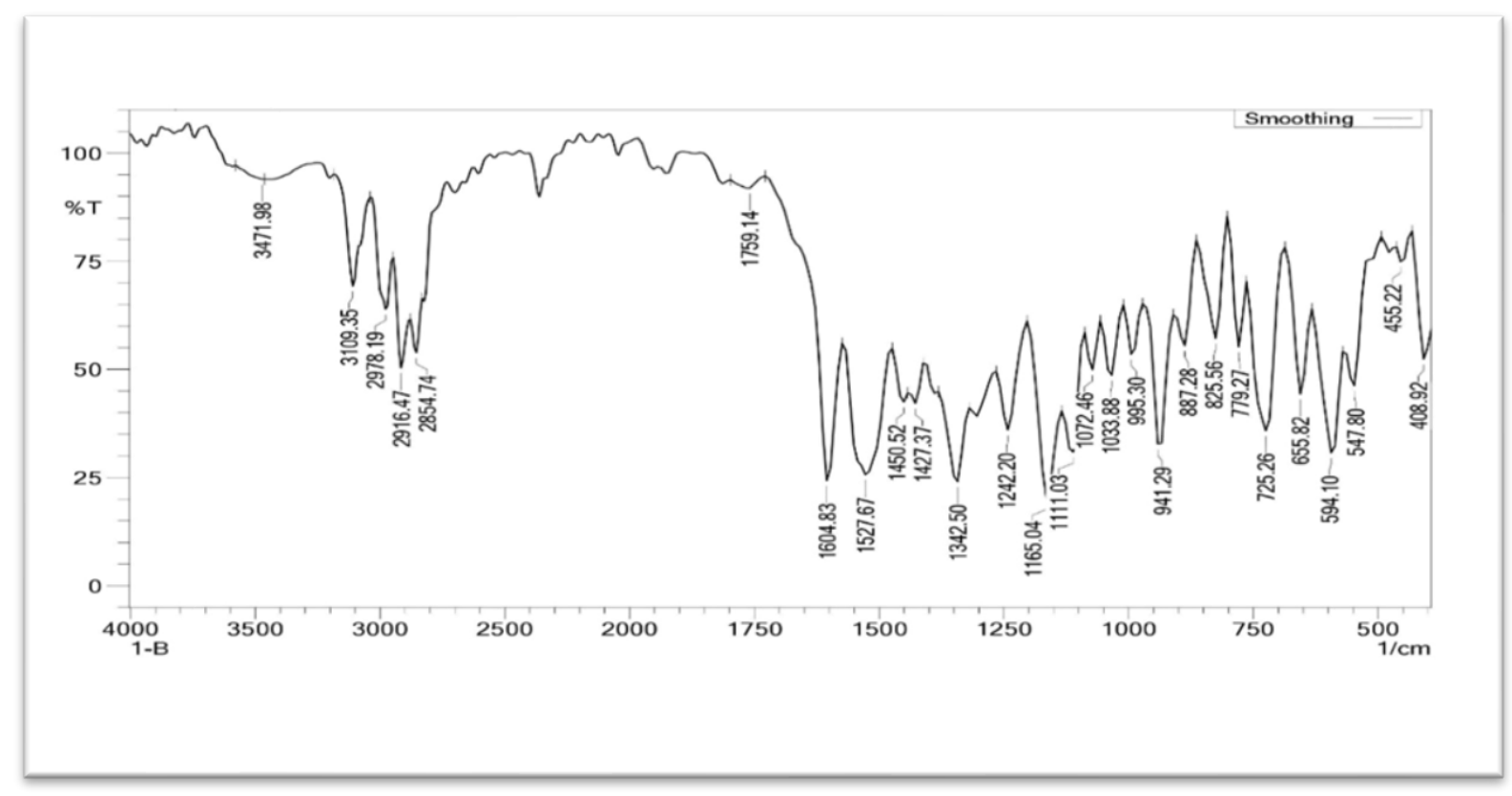

Figure 02 : IR spectrum for synthesized drug

Various peaks starting from $779 \mathrm{~cm}^{-1}$ to $3092 \mathrm{~cm}^{-1}$ were observed. C-H stretching was observed at 3109 , 2978,2916, 2854 and, $1604 \mathrm{~cm}^{-1}$ which are indicating the aromatic and aliphatic compounds respectively. The identification of functional group is shown in table 03.

Table 03: Functional Group detection through IR Frequency

\begin{tabular}{|c|c|}
\hline Vibrating frequency $\left(\mathrm{cm}^{-1}\right)$ & Functional group \\
\hline 3109 & $\begin{array}{c}\text { Aromatic C }-\mathrm{H} \\
\text { Stretching }\end{array}$ \\
\hline 2978 & Aliphatic C $-\mathrm{H}$ \\
2916 & Stretching \\
2854 & C = C Stretching \\
\hline 1604 & NO2 Stretching \\
\hline 1527 & S=O Stretching \\
\hline 1342 & \\
\hline
\end{tabular}


NMR- Spectra

The $1 \mathrm{H}$ NMR spectrum was recorded for synthesized drug (Figure 03) and interpretation is shown in table 04 .

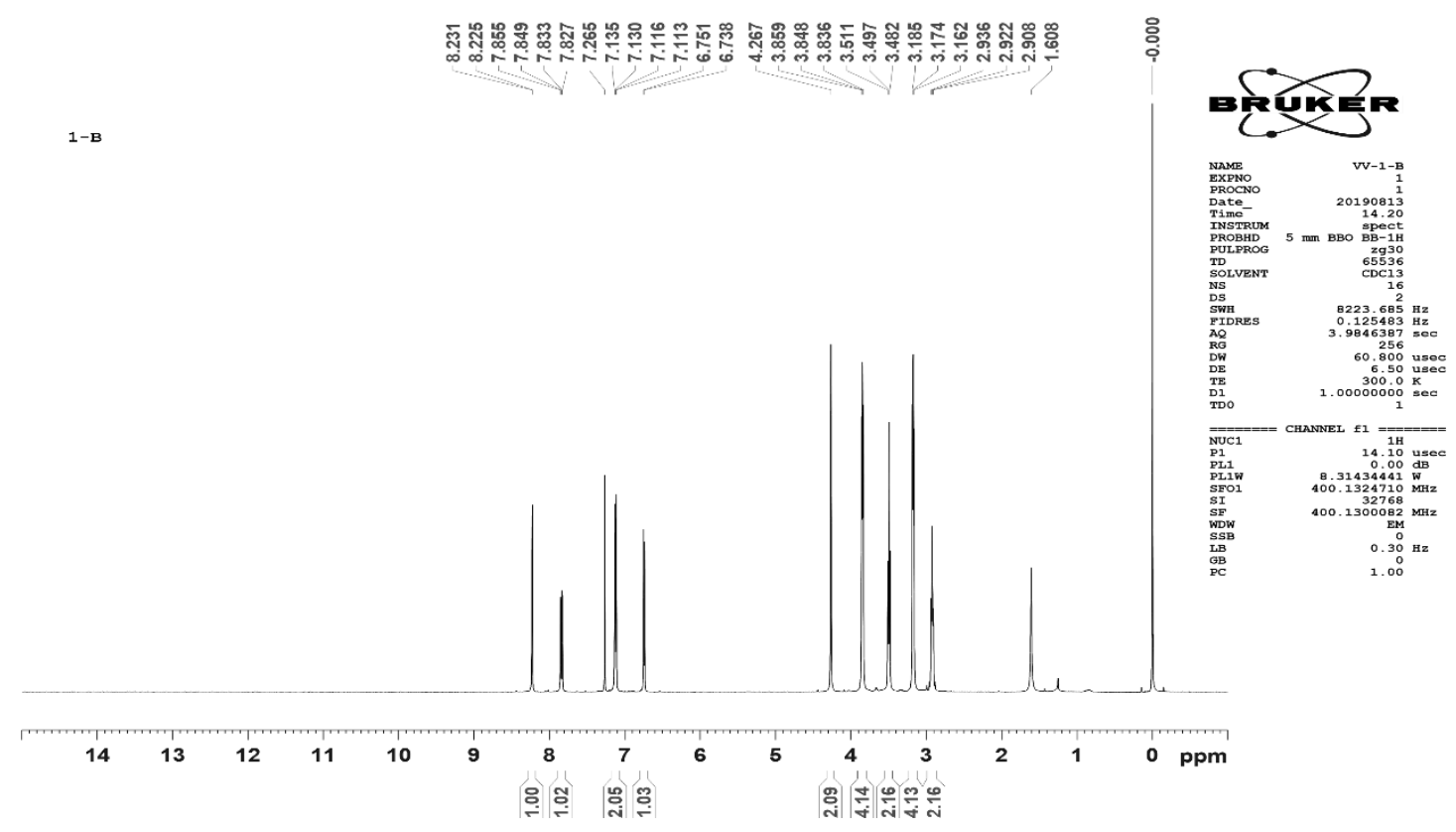

Figure 03 : 1H NMR spectrum

In $1 \mathrm{H}$ NMR, eight types of protons were identified among which most protons were found to be doublet. Four triplet protons were identified between 2.904-2.932 ppm and maximum chemical shift were reported 7.943-7.917 ppm. The $1 \mathrm{H}$ interpretations are shown in table 04.

Table 04: $1 \mathrm{H}$ NMR data interpretation

\begin{tabular}{|c|c|c|c|}
\hline Sr. No. & $\begin{array}{c}\text { Signal Position } \\
(\boldsymbol{\delta} \mathbf{n n m})\end{array}$ & $\begin{array}{c}\text { Relative No. } \\
\text { Of Protons }\end{array}$ & Multiplicity \\
\hline 1 & $8.231-8.225$ & $1 \mathrm{H}$ & Doublet \\
\hline 2 & $7.855-7.827$ & $1 \mathrm{H}$ & Doublet \\
\hline 3 & $7.135-7.113$ & $2 \mathrm{H}$ & Doublet \\
\hline 4 & $6.751-6.738$ & $1 \mathrm{H}$ & Doublet \\
\hline 5 & 4.267 & $2 \mathrm{H}$ & Singlet \\
\hline 6 & $3.859-3.836$ & $4 \mathrm{H}$ & Triplet \\
\hline 7 & $3.511-3.482$ & $2 \mathrm{H}$ & Triplet \\
\hline 8 & $3.185-3.162$ & $4 \mathrm{H}$ & Triplet \\
\hline 9 & $2.936-2.90$ & $2 \mathrm{H}$ & Triplet \\
\hline
\end{tabular}

13C NMR were recorded for synthesized drug in Bruker base NMR model which is shown in figure 04 and interpretation is recorded in table 05. 


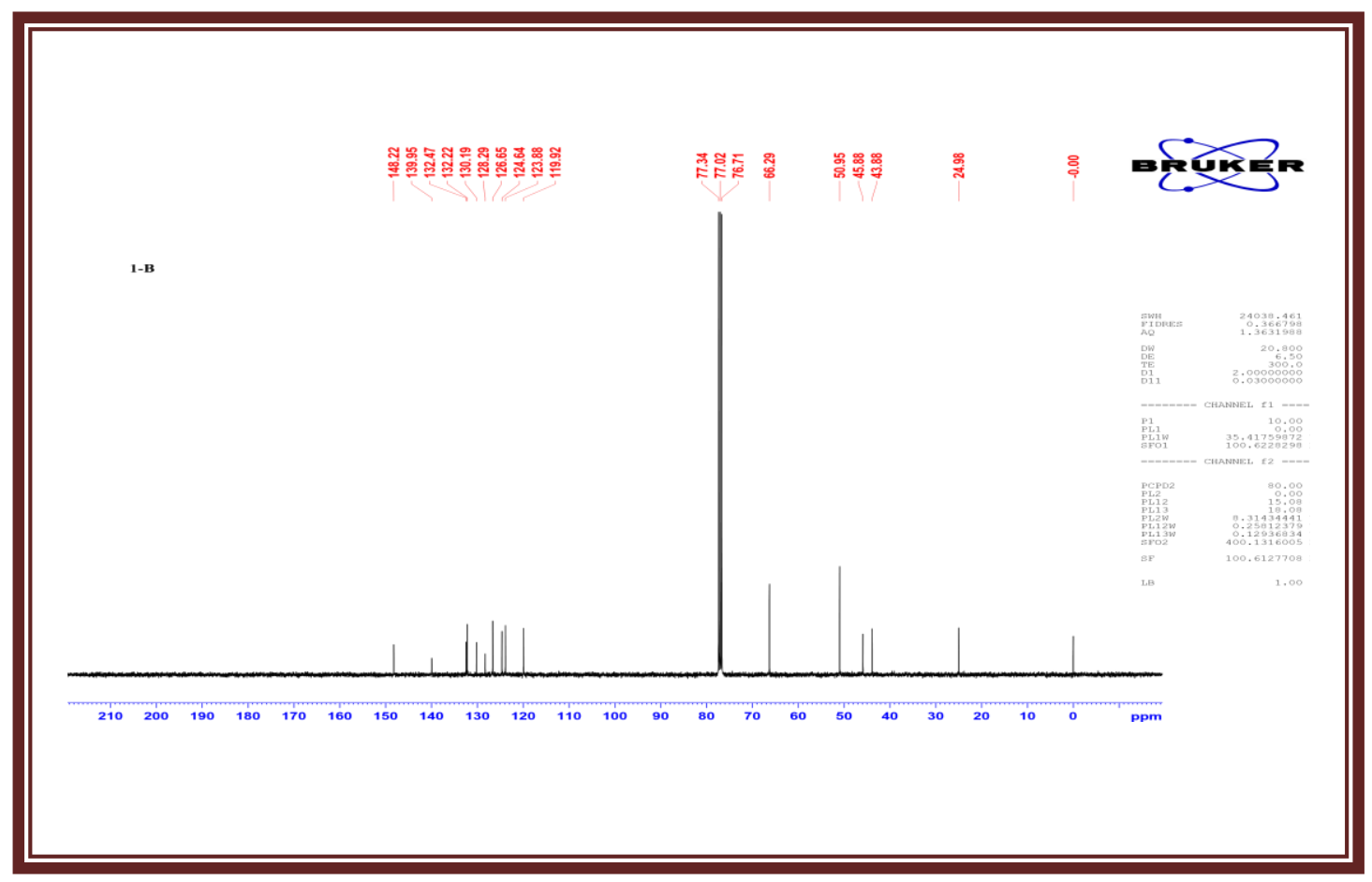

Figure 04 : 13C NMR spectrum

Table 05: 13C NMR data interpretation

\begin{tabular}{|c|c|}
\hline$\delta$ value & Carbon Assignment \\
\hline 24.98 & 14 \\
\hline 43.88 & 15 \\
\hline 45.88 & 11 \\
\hline 50.95 & 1,4 \\
\hline 66.29 & 2,3 \\
\hline 119.92 & 6 \\
\hline 123.88 & 9 \\
\hline 124.64 & 7 \\
\hline 126.65 & 16 \\
\hline 128.29 & 12 \\
\hline 130.19 & 13 \\
\hline 132.22 & 17 \\
\hline 132.47 & 8 \\
\hline 139.95 & 5 \\
\hline 148.22 & 10 \\
\hline
\end{tabular}




\section{Mass spectroscopy:}

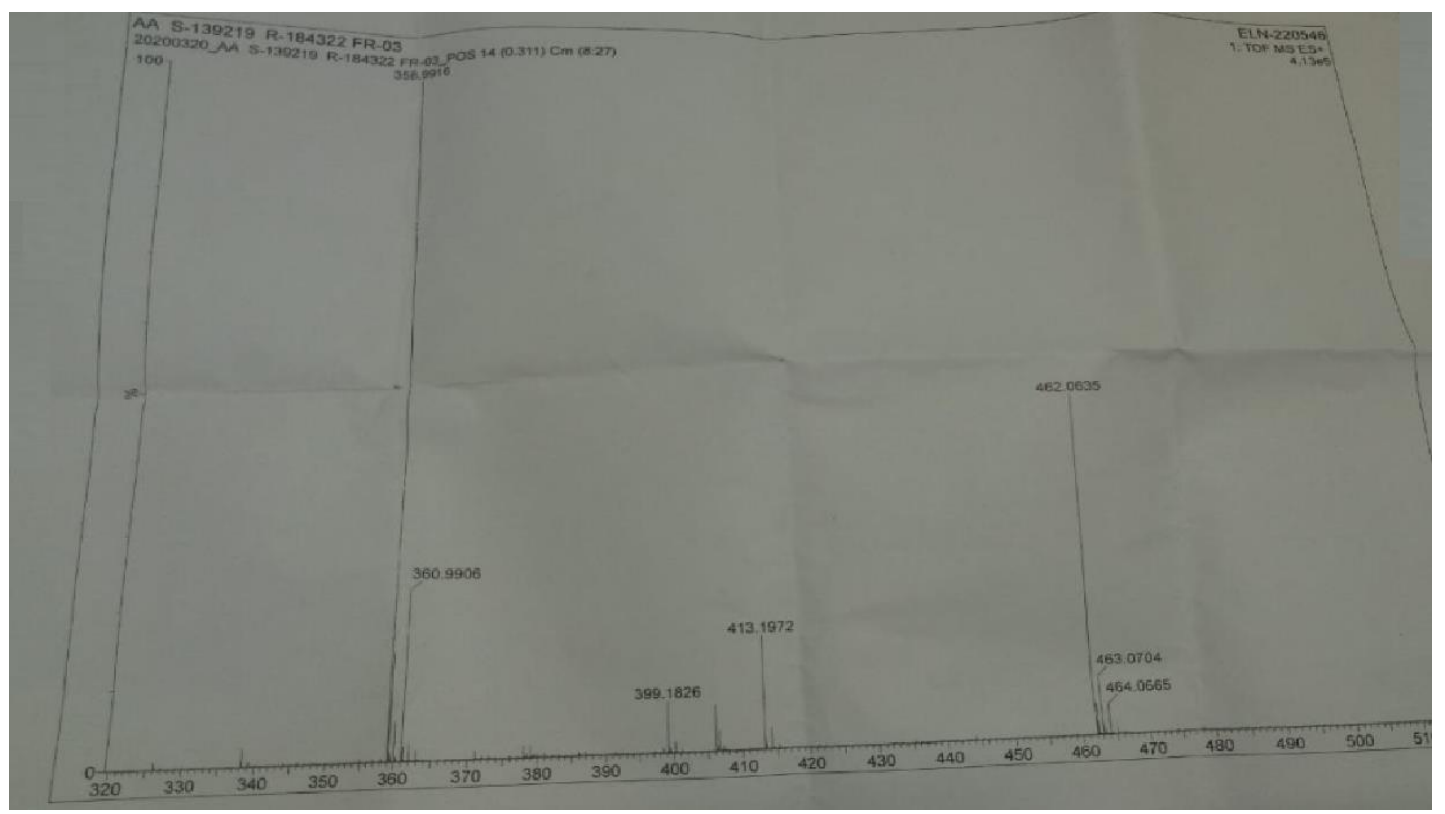

Figure 06 : Mass spectral study of pyridine derivative

\section{HPLC method validation}

A number of test runs were conducted utilizing reversed columns of $\mathrm{C} 18$, varied proportions of mobile phases and varying rates of circulation for the synthesized pyridine derivative separation with appropriate chromatographical characteristics such as resolution, theoretical plate, and the tail factor.The chromatogram ofthe optimized method is presented in Figure 07.

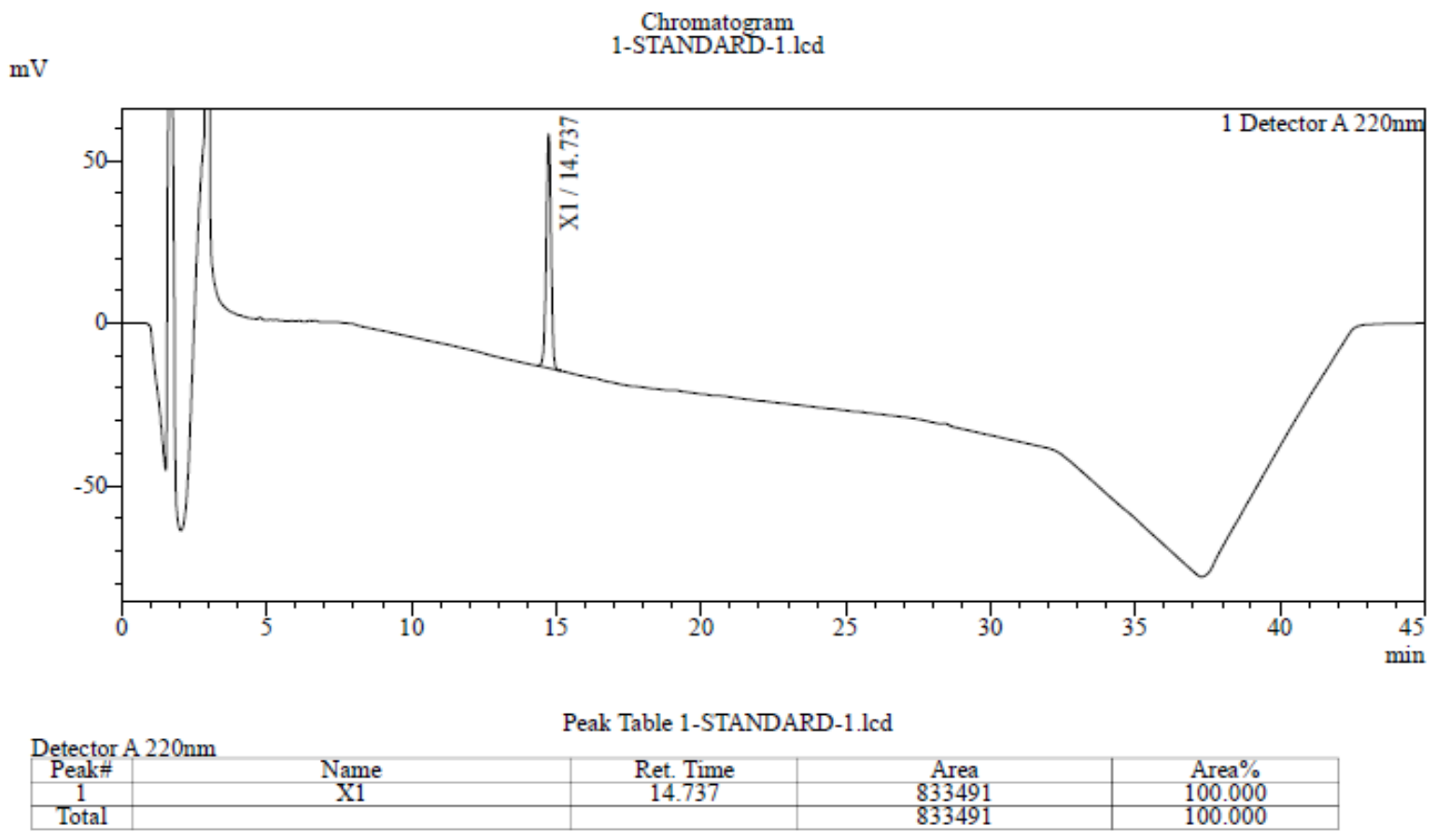

Figure 07 : HPLC Chromatogram 


\section{Precision Study}

Repeatability (intra-day precision) was determined by injecting six replicate $(n=6)$ solutions of the standard concentration which is shown in various sections. The system precision is shown in table 06 , method precision is shown by figure 08 and table 07 .

Table 06: System precision

\begin{tabular}{|c|c|}
\hline Injection No. & Area response of Drug Substance \\
\hline 1 & 833491 \\
\hline 2 & 834007 \\
\hline 3 & 834123 \\
\hline 4 & 834248 \\
\hline 5 & 834183 \\
\hline 6 & 834284 \\
\hline Mean & 834056 \\
\hline \%RSD & 0.035 \\
\hline
\end{tabular}
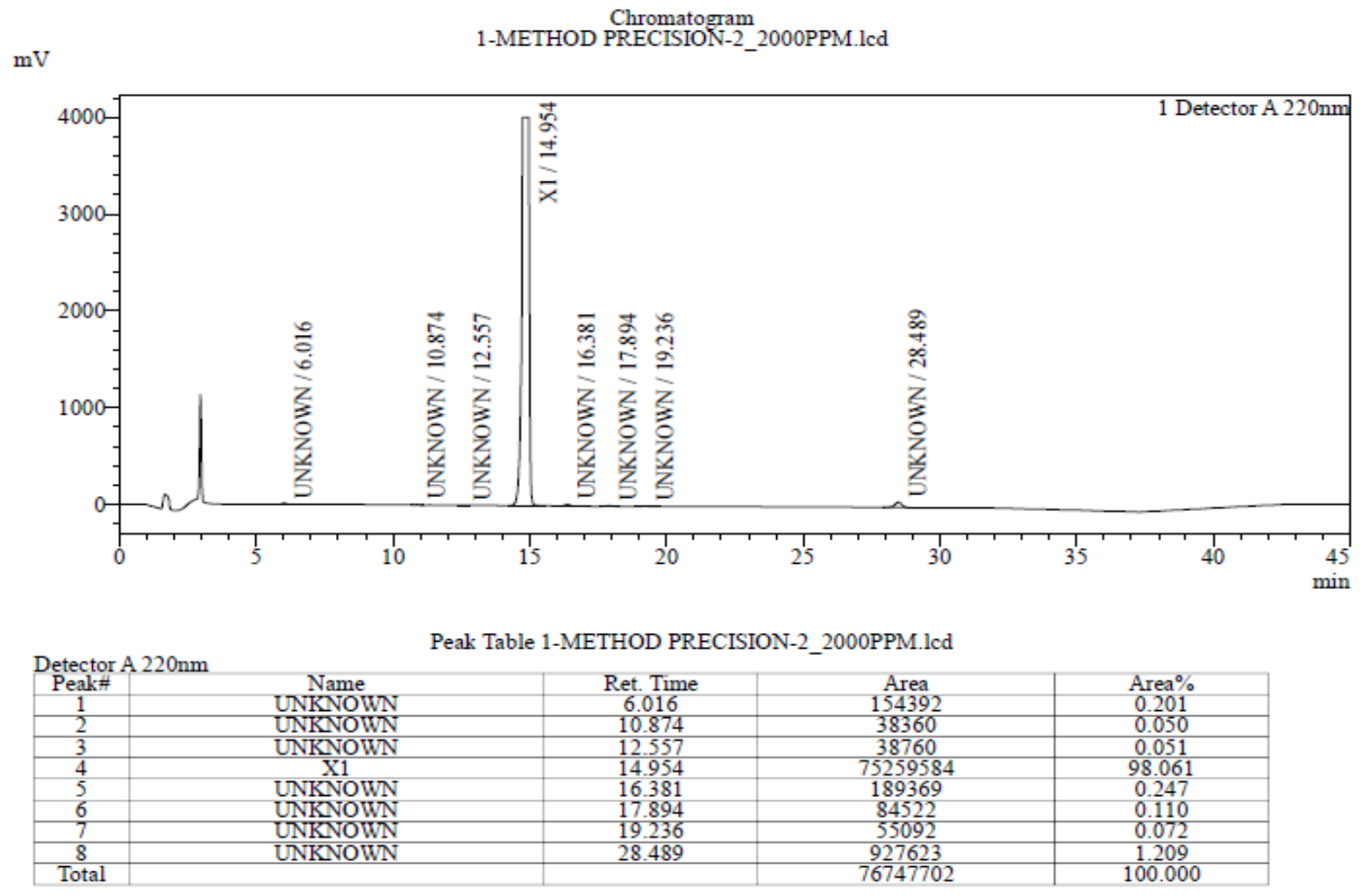

Figure 08 : Chromatogram of the optimized method 
Table 07: method precision

\begin{tabular}{|c|c|c|c|c|c|c|c|}
\hline Name & $\begin{array}{c}\text { Un } \\
\text { Known } \\
(\text { RRT- } \\
\mathbf{0 . 4 0})\end{array}$ & $\begin{array}{c}\text { Un } \\
\text { Known } \\
(\text { RRT- } \\
\mathbf{0 . 7 3})\end{array}$ & $\begin{array}{c}\text { Known } \\
(\text { RRT- } \\
\mathbf{0 . 8 4}\end{array}$ & $\begin{array}{c}\text { Un } \\
\text { Known } \\
(\text { RRT- } \\
1.09)\end{array}$ & $\begin{array}{c}\text { Un } \\
\text { Known } \\
(\text { RRT- } \\
1.20)\end{array}$ & $\begin{array}{c}\text { Un } \\
\text { Known } \\
(\text { RRT- } \\
1.29)\end{array}$ & $\begin{array}{c}\text { Un } \\
\text { Known } \\
(\text { RRT- } \\
1.91)\end{array}$ \\
\hline Set-1 & 153734 & 38655 & 38902 & 189657 & 84320 & 54986 & 927955 \\
\hline Set-2 & 154392 & 38360 & 38760 & 189369 & 84522 & 55092 & 927623 \\
\hline Set-3 & 154366 & 38407 & 38652 & 189451 & 84093 & 55704 & 928243 \\
\hline Set-4 & 154426 & 38576 & 38535 & 189662 & 84092 & 55956 & 928721 \\
\hline Set-5 & 154321 & 38283 & 38808 & 189717 & 84236 & 55699 & 928590 \\
\hline Set-6 & 154383 & 38379 & 38817 & 189613 & 84143 & 56488 & 929112 \\
\hline Mean & 154270 & 38443 & 38746 & 189578 & 84234 & 55654 & 928374 \\
\hline \% RSD & 0.17 & 0.37 & 0.34 & 0.07 & 0.20 & 1.00 & 0.06 \\
\hline
\end{tabular}

\section{LOD and LOQ}

The LOD-LOD chromatogram for test samples are shown in figure $09,10,11,12$ as well as in 13 and, the data are indicating in table 08,09 and, 10.
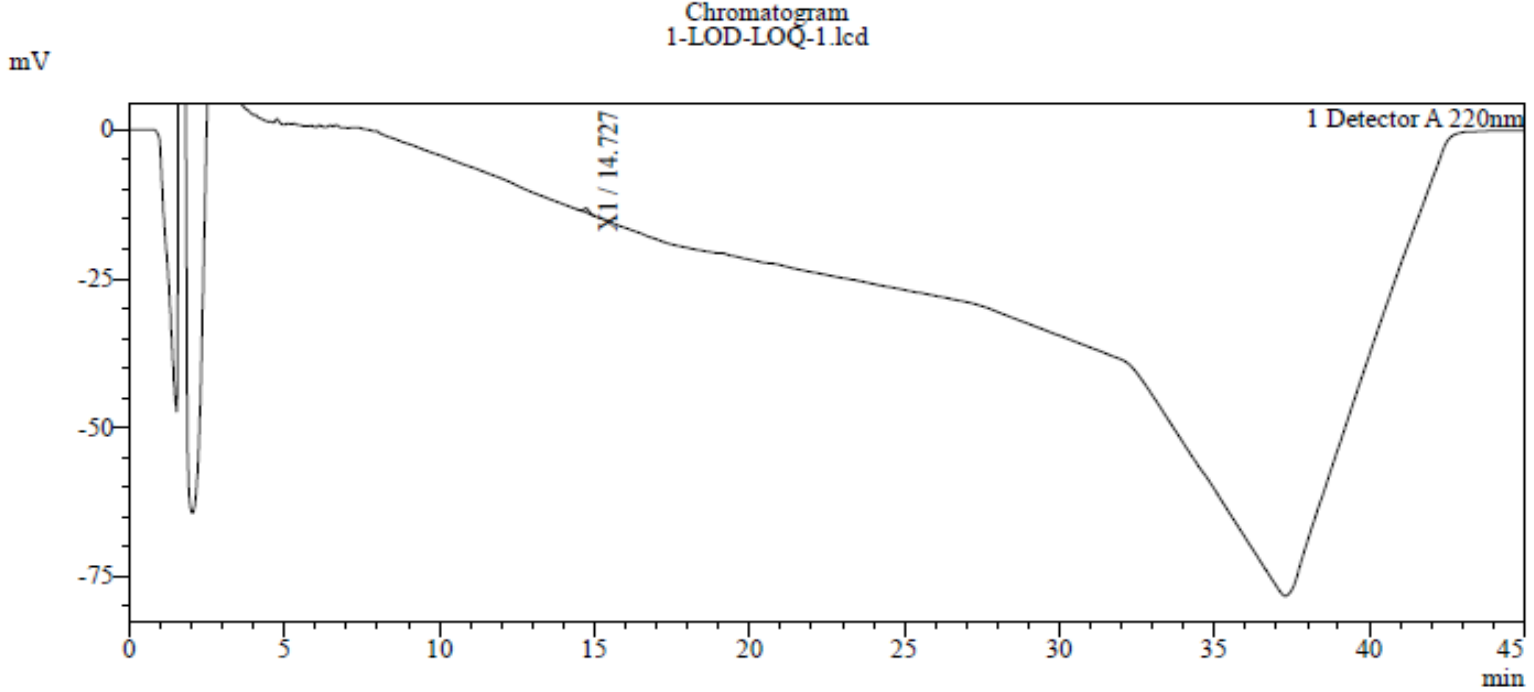

Peak Table 1-LOD-LOQ-1.lcd

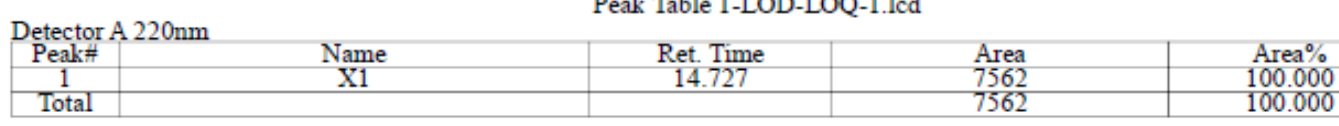

Figure 09 : Chromatogram of LOD-LOQ-01 
$\mathrm{mV}$

Chromatogram

1-LOD-LOQ-2.lcd

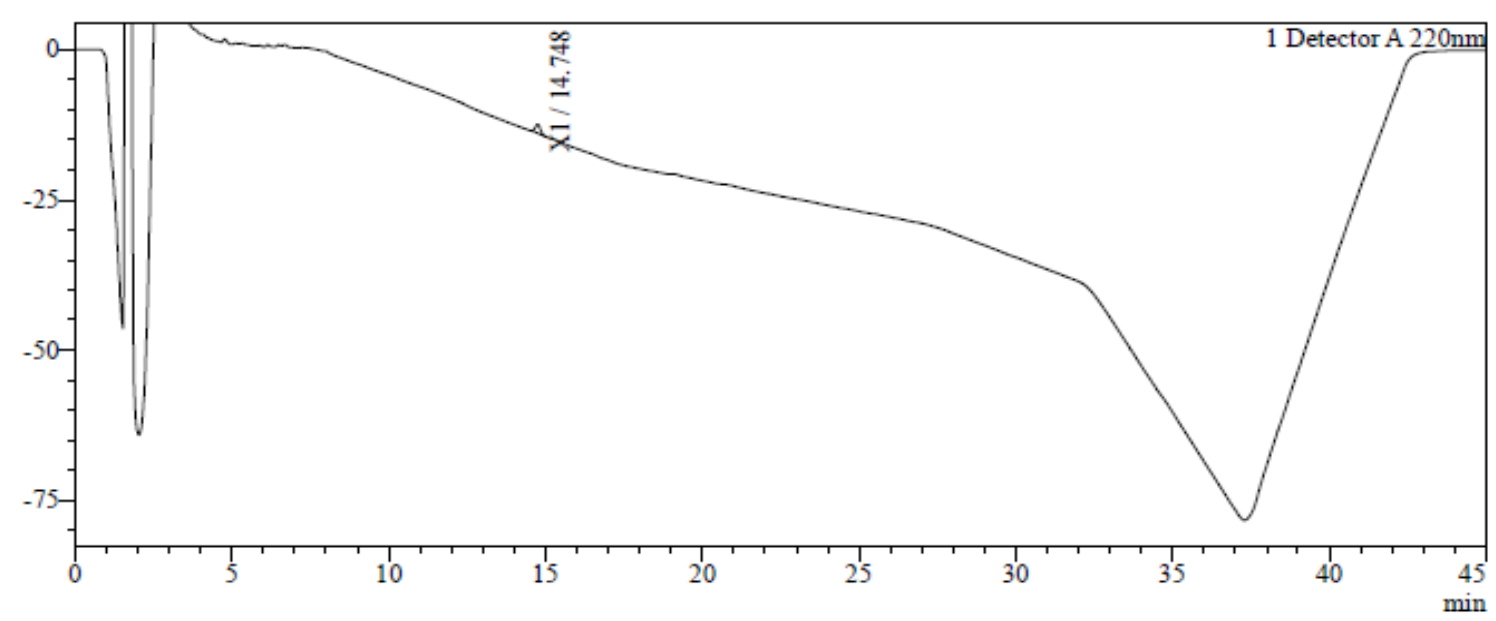

Peak Table 1-LOD-LOQ-2.lcd

\begin{tabular}{|c|c|c|c|c|}
\hline & & 1avie $1-L$ & & \\
\hline $\begin{array}{l}\text { Detector } \\
\text { Peak }\end{array}$ & Name & Pet Tim & Aren & Arego \\
\hline 1 & $\mathrm{X} 1$ & 14.748 & 16346 & 100.000 \\
\hline Total & & & 16346 & 100.000 \\
\hline
\end{tabular}

Figure 10 : Chromatogram of LOD-LOQ-02

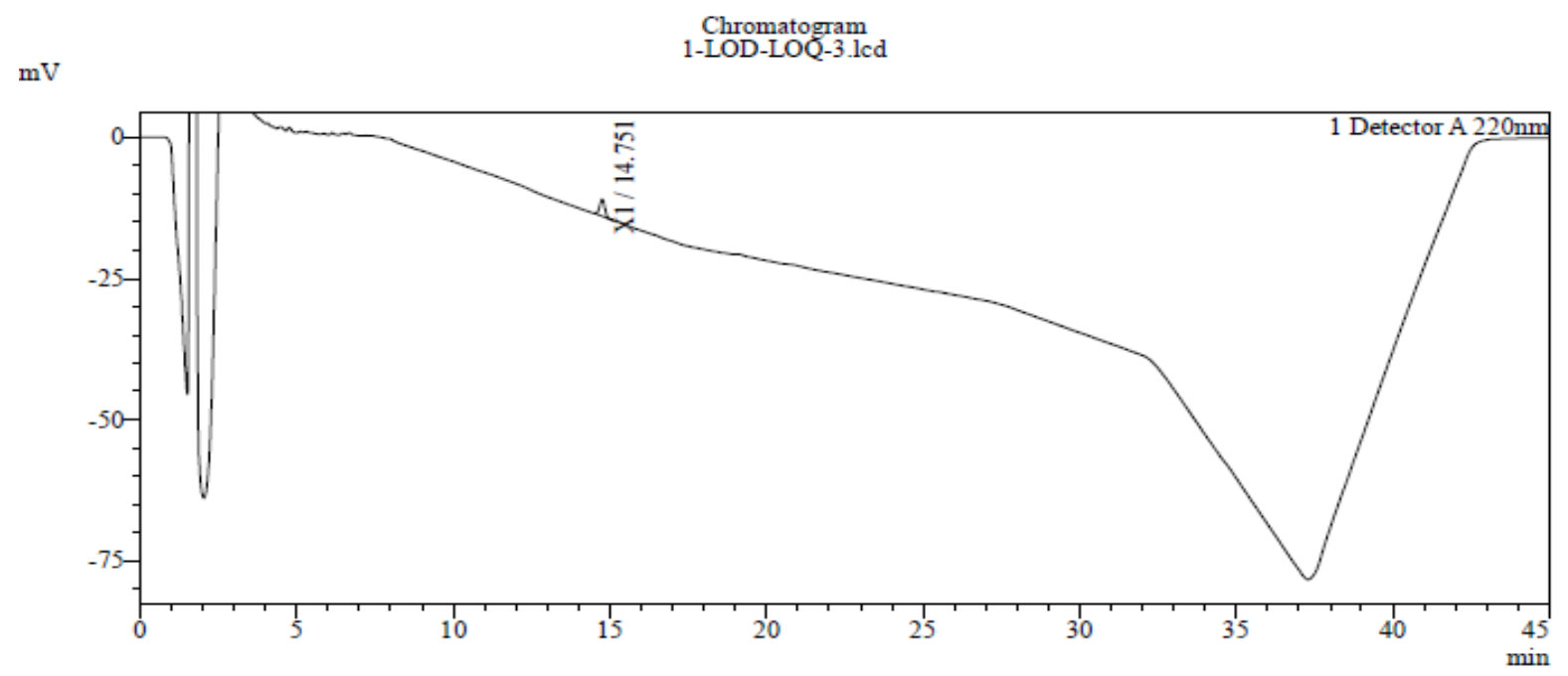

Peak Table 1-LOD-LOQ-3.lcd

\begin{tabular}{|c|c|c|c|c|}
\hline \multicolumn{5}{|c|}{ 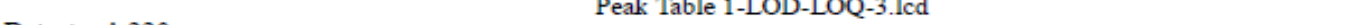 } \\
\hline Detector & & & & \\
\hline $\begin{array}{c}\text { Peak } \# \\
1\end{array}$ & $\underset{\mathrm{X} 1}{\text { Name }}$ & $\begin{array}{c}\text { Ret. Time } \\
14.751\end{array}$ & $\begin{array}{l}\text { Area } \\
33568\end{array}$ & Area \% \\
\hline Total & & & 33568 & 100.000 \\
\hline
\end{tabular}

Figure 11 : Chromatogram of LOD-LOQ-03 
$\mathrm{mV}$

Chromatogram

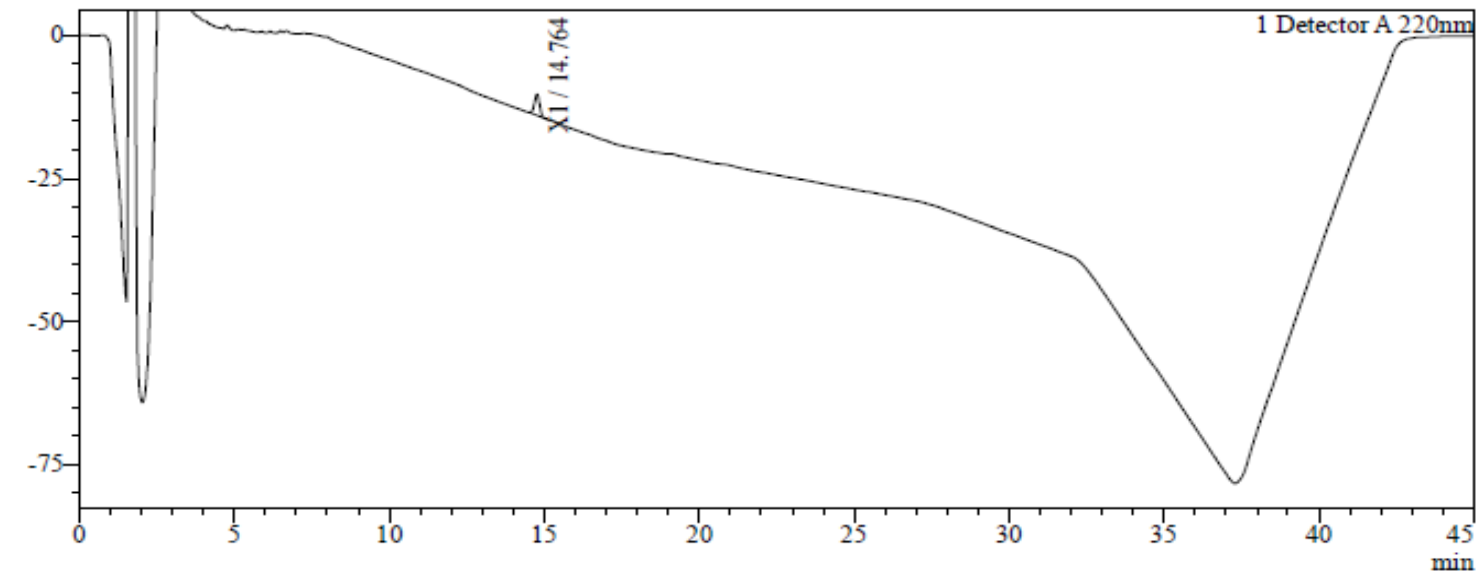

Peak Table 1-LOD-LOQ-4.led

\begin{tabular}{|c|c|c|c|c|}
\hline \multicolumn{5}{|c|}{ 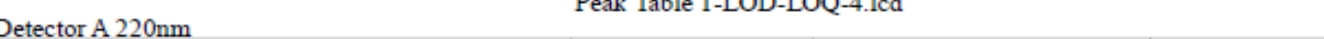 } \\
\hline Peak\# & Name & Ret. Time & Area & \\
\hline 1 & $\mathrm{X} 1$ & 14.764 & 42189 & 100.000 \\
\hline Total & & & 42189 & 100.000 \\
\hline
\end{tabular}

Figure 12 : Chromatogram of LOD-LOQ-04

$\mathrm{mV}$

Chromatogram
1-LOD-LOQ-5.lcd
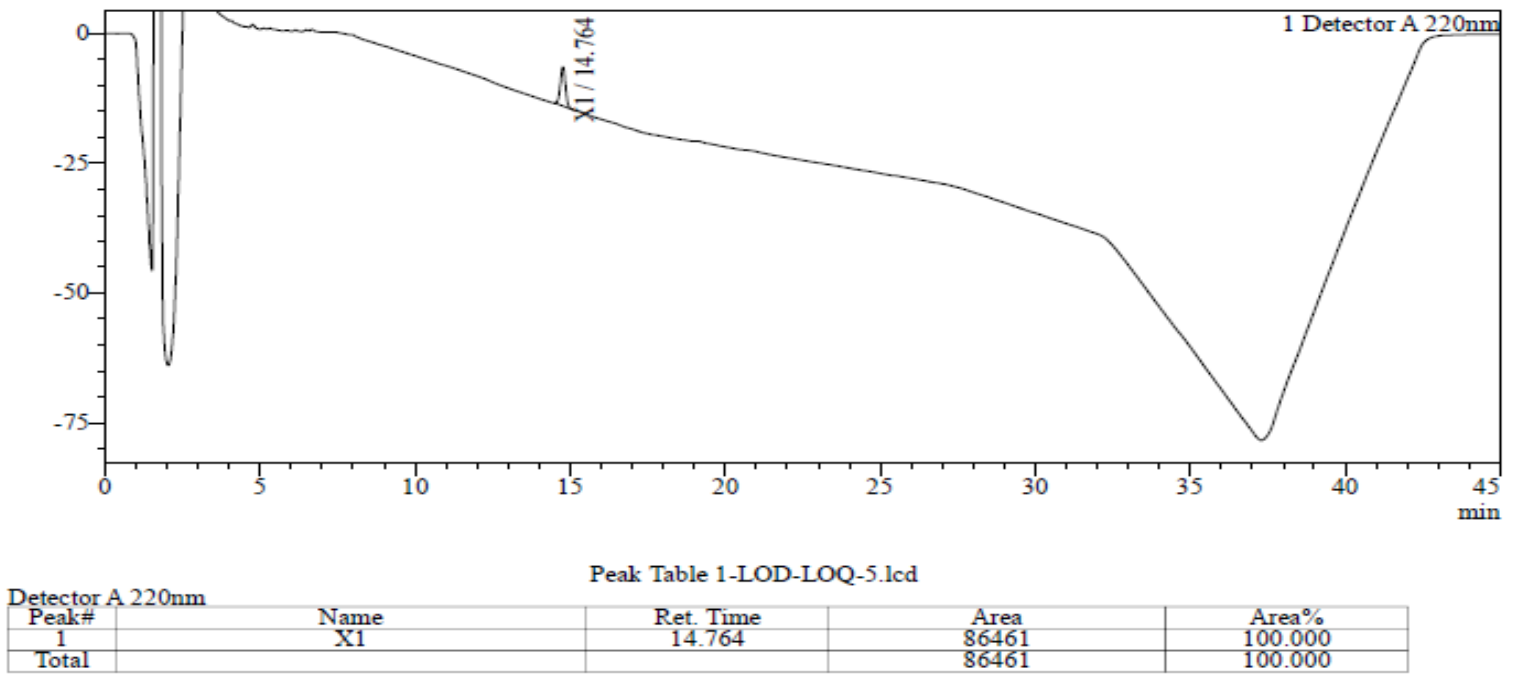

Figure 13 : Chromatogram of LOD-LOQ-05

Table 08 : LOD and LOQ Determination for standard preparation

\begin{tabular}{|c|c|c|}
\hline \multicolumn{2}{|c|}{ Standard Solution } \\
\hline Sr. No. & Conc. (ppm) & Area Response \\
\hline 1 & 0 & 0 \\
\hline
\end{tabular}


R. S. Dave et al Int J Sci Res Sci \& Technol. May-June-2021, 8 (3) : 528-542

\begin{tabular}{|c|c|c|}
\hline 2 & 0.208 & 7562 \\
\hline 3 & 0.416 & 16346 \\
\hline 4 & 0.832 & 33568 \\
\hline 5 & 1.040 & 42189 \\
\hline 6 & 2.080 & 86461 \\
\hline \multicolumn{2}{|c|}{ Slope } & 41769.45153 \\
\hline & Intercept & -835.1683673 \\
\hline \multicolumn{2}{|c|}{ Squared CC* } & 0.99974 \\
\hline
\end{tabular}

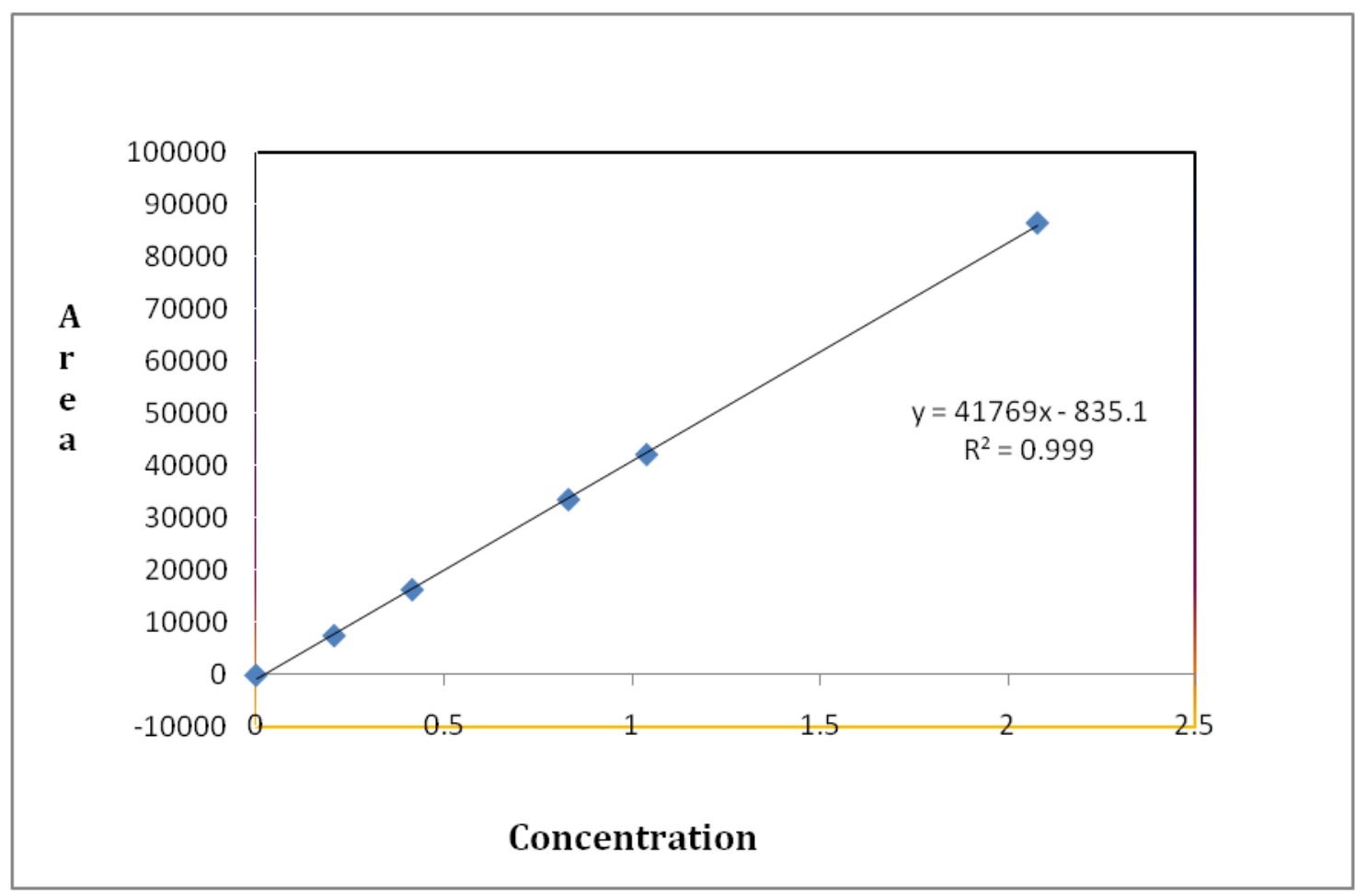

$$
\mathrm{X} \text { axis }=\text { Concentration }(\mu \mathrm{g} / \mathrm{ml}) \quad \mathrm{Y} \text { axis }=\text { PeakArea }
$$

Figure 14 : Regression Analysis chart of linearity Study included with LOQ level 
R. S. Dave et al Int J Sci Res Sci \& Technol. May-June-2021, 8 (3) : 528-542

Table 09 : Limit of Detection and Limit of Quantification for standard

\begin{tabular}{|c|c|c|}
\hline \multirow{2}{*}{ \% Level } & \multicolumn{2}{|c|}{ Reported } \\
\cline { 2 - 3 } & $\mathrm{ppm}$ & $\%$ \\
\hline LOD & 0.400 & 0.020 \\
\hline LOQ & 0.800 & 0.040 \\
\hline
\end{tabular}

Table 10 : Observation at LOD and LOQ Precision

\begin{tabular}{|c|c|c|}
\hline \multirow{2}{*}{ Sr. No. } & \multicolumn{2}{|c|}{ Standard } \\
\cline { 2 - 3 } & LOD Precision & LOQ Precision \\
& Area Response & Area Response \\
\hline 1 & 16346 & 33432 \\
\hline 2 & 16123 & 33626 \\
\hline 3 & 16234 & 33795 \\
\hline 4 & 16312 & 33576 \\
\hline 5 & 16107 & 33548 \\
\hline 6 & 16289 & 33638 \\
\hline Mean & 16235 & 33602 \\
\hline \%RSD & 0.62 & 0.35 \\
\hline
\end{tabular}

\section{IV.CONCLUSION}

A new RP-HPLC method for the accurate detection of5 - (4 -morpholin -4 - yl )- 3- Nitrobenzene - 1 Sulfonyl) - 4, 5, 6, 7 -Tetrahydrothieno [3, 2 - C] effectively developed and validated in this work.The proposed approach is said to have been straightforward, accurate, and precise.The developed approach is devoid of excipients, contaminants, or active chemicals that could create difficulties. The 
optimized formulation is also said to be accurate, genuine, and trustworthy.

\section{REFERENCES}

[1]. Ingale SJ, Sahu CM, Paliwal RT, Vaidya S, Singhai AK. Advance approaches for the impurity profiling of pharmaceutical drugs: A review. International Journal of Pharmacy and Life Sciences.2011;2(7): 955-962.

[2]. Prakasha A, Nandia U, Teotiaa AK, Javed AF, Singh GN. Forced Degradation Study of Emtricitabine For Evaluation Of Genotoxic Impurity In Active Pharmaceutical Ingredient's (API) Shelf Life. WJPPS.2015; 4(7): 1909-1919.

[3]. Maggio RM, Calvo NL, Vignaduzzo SE, Kaufman TS. Pharmaceutical impurities and degradation products: Uses and applications of NMR techniques. J Pharm Biomed Anal 2014;101: 102-122.

[4]. Kalyana CE, Srinivasa RVND, Sachin BS, Shailesh WG, Shailendra KS, et al. Synthesis and characterization of process related impurities of an antituberculosis drugProthionamide. Der Pharma Chemica.2015; 7(3): 79-84.

[5]. KatritzkyAR, Rees CW, Scriven EFV, McKillopA, JonesG. In Comprehensive Heterocyclic Chemistry II, PergamonOxford. 1996;5,167.

[6]. Boger DL. Heterocyclic and acyclic azadiene diels-alder reactions: Total synthesis of nothapodytine B. 1998;35(5), 1003-1011. doi:10.1002/jhet.5570350502

[7]. Ahmad MZ, Hamid KA, Effendi TA. A ValidatedHigh-performance Liquid Chromatographic Method for the Determination of Levodopa in Rat Plasma and its Application in Pharmacokinetic Studies. Bandung: 2012 IEEE Symposium on Business, Engineering and Industrial Applications; 2012;134-9.
[8]. Rudrapal M, Oduri MU, Samidala NR, Kiran BV,Junejo JA, Singh KD, et al. Development and validation of RP-HPLC method for simultaneous estimation of olmesartan and hydrochlorothiazide in tablet dosage form. Orient J Chem 2015; 31:921-6.

[9]. Surya Kiran BVVS, Sridhar N, Raghavendra M,Rudrapal M. Development and validation of a RP-HPLC method for simultaneous estimation of minoxidil and aminexil in topical formulation. Asian J Chem 2016; 28:157-60.

[10]. Green JM. A practical guide to analytical methodvalidation. Anal Chem 1996; 689:305A9.

[11]. International Conference on Harmonization. TechnicalRequirements for the Registration of Pharmaceuticals for Human Use, Validation of Analytical Procedures: Methodology, ICH-Q2B. Geneva: International Conference on Harmonization; 1996.

[12]. Wegscheider W. Validation of analytical methods. In:Guenzler $\mathrm{H}$, editor. Accreditation and Quality Assurance in Analytical Chemistry. Berlin: Springer Verlag; 1996.

[13]. Michael E. Analytical method development. In: Swartz,Ira SK, editors. Analytical Method Development and Validation. 1st ed. New York: Marcel Dekker Inc.; 2009.

[14]. Parida RK. Overview of pharmaceutical validationand process controls in drug development. Pharm Sin 2010; 1:11-9.

\section{Cite this article as :}

R. S. Dave, Vipul J. Vyas, Bipinchandra Mahyavanshi, "Development and Validation of Reverse-phase Highperformance Liquid Chromatography Method for Novel Synthetic Pyridine Derivative", International Journal of Scientific Research in Science and Technology (IJSRST), Online ISSN : 2395-602X, Print ISSN : 2395-6011, Volume 8 Issue 3, pp. 528-542, May-June 2021. Available at doi : https://doi.org/10.32628/IJSRST2183127 Journal URL : https://ijsrst.com/IJSRST2183127 